\title{
KONSEP PEMIKIRAN FILSAFATI \\ MUHAMMAD IQBAL TENTANG PENDIDIKAN \\ DAN RELEVANSINYA DENGAN PEMBANGUNAN \\ KARAKTER BAGI BANGSA INDONESIA
}

\section{Widyastini}

Fakultas Filsafat, Universitas Gadjah Mada Yogyakarta

Email: fatimahwidyastini@gmail.com

\begin{abstract}
Abstrak
Penelitian ini bertujuan untuk menemukan hal yang baru dalam pandangan Muhammad I qbal tentang pendidikan dan relevansinya dengan pembangunan karakter bagi bangsa Indonesia, serta melakukan evaluasi kritis terhadap pemikiran Muhammad Iqbal tentang pendidikan yang terdapat dalam beberapa karyanya. Metode penelitian yang digunakan adalah penelitian pustaka dengan menggunakan metode hermeneutika. Hasil penelitian ini adalah pendidikan menurut pandangan Muhammad Iqbal seharusnya diarahkan untuk menghidupkan kembali dan menguatkan individualitas manusia serta menemukan dan merevitalisasi sumber-sumber kebudayaan nasional dengan memberikan manfaat sehingga menghasilkan aktifitas yang kreatif. Hakikat pemikiran Muhammad Iqbal tentang pendidikan dan relevansinya dengan pembangunan karakter bagi bangsa Indonesia dapat memberikan inspirasi setiap manusia Indonesia agar senantiasa dapat mawas diri terhadap pendidikan yang selama ini dilaksanakan, sehingga dapat terwujud suasana pendidikan yang sesuai dengan nilai-nilai luhuryang terdapat dalam sila-sila Pancasila.
\end{abstract}

Kata kunci:pendidikan, individualitas, nilai-nilailuhur

\section{Abstract}

This research aims to find a new thing in Muhammad Iqbal's view of education and its relevance to characters building for Indonesian, and also to do a critical evaluation to his thought of education in his books. The method of this research is library research using hermeneutics method. The result of this research is education, according to Muhammad Iqbal, should be directed to revive and support human individuality, and to find sources of national culture with giving benefit so that it brings creative activities. The essence of Muhammad Iqbal's thought about education and its relevance to the characters building of Indonesian could give inspiration to every people of Indonesia in order to do self correction toward recent education implementation so that it will be realized the edu- 
cation which accord with the noble values of Pancasila.

Keywords: education, individuality, noble values.

\section{PENDAHULUAN}

Aslam Hady dalam Syed Abdul Walid mengatakan bahwa Muhammad Iqbal lahir pada tanggal 9 Nopember 1877 atau 3 Dzul'qaidah tahun 1294 H di Sialkot Punjab (Hady, 1988: 7). Perjalanan intelektual Muhammad Iqbal dimulai dari pendidikan dasar di Sialkot, Punjab. Ia kemudian melanjutkan sekolah ke Lahore di Government College yang dibimbing oleh Sir Thomas Arnold, seorang filsuf dan orientalis yang terkenal pada waktu itu. Muhammad Iqbal memperoleh gelar MA pada tahun 1899, lalu menjadi dosen di Oriental College Lahore pada bidang Bahasa Arab (Hady, 1988: 8).

Muhammad Iqbal pada tahun 1905 belajar di Universitas Cambridge, Inggris, mendalami ilmu filsafat. Dua tahun kemudian ia melanjutkan studi ke Munich (Jerman) dan berhasil meraih gelar Doktor (Ph.D) dalam ilmu tasawuf dengan disertasi berjudul The Development of Metaphysics in Persia.

Muhammad Iqbal pada tahun 1908 kembali ke Lahore (India) bekerja sebagai pengacara dan dosen filsafat. Karyanya yang berjudul The Reconstruction of Religious Thought in Islam adalah kumpulan ceramah di beberapa universitas di India.

Muhammad Iqbal ketika belajar di Lahore berada dalam bimbingan Sir Thomas Arnold, pengarang The Preaching of Islam. Ia adalah Guru Pertama yang mengenalkan Filsafat Barat kepada Muhammad Iqbal, seperti ulama Mirr Hasan di Sialkot yang memberikan ilmu pengetahuan tentang Islam. Muhammad Iqbal pada tahun 1905 pergi ke Eropa atas nasehat Sir Thomas Arnold untuk belajar Filsafat Barat di Trinity College Universitas Cambridge sambil kuliah ilmu hukum di Lincoln's Iinn, London. Selama tiga tahun belajar di Eropa menjadikan alam pemikirannya semakin luas dan mendalam. Hal ini karena ia tidak hanya kuliah di Universitas Cambridge, namun secara antusia ia juga menuntut berbagai macam ilmu pengetahuan di Cambridge, London dan Jerman. (Raliby, 1978: 13-15). 
Iqbal melihat perkembangan keadaan dunia pada waktu itu, terhadap kehidupan berbagai bangsa. Hal itu telah mengubahnya menjadi membenci paham nasionalisme sempit (chauvinism) yang merupakan sumber malapetaka politik Internasional. Iqbal kemudian tertarik kepada pergerakan dan perjuangan berbagai bangsa yang dijajah dan ditindas. Tiga tahun di Eropa, ia menyempatkan diri mengajar bahasa Arab selama enam bulan di Universitas London. Sebelum kembali ke Lahore pada bulan Agustus 1908 ia berkesempatan memberikan peringatan kepada bangsa Eropa terhadap akibat yang akan menimpa dunia Barat, jika tetap berpegang pada paham materialisme. (Raliby, 1978: 15). Iqbal menulis puisi sebagai berikut:

"Wahai bangsa Barat,

Bumi Tuhan bukanlah toko,

Emas yang engkau sangka murni,

Kini ternyata bernilai rendah,

Kebudayaan bekal bunuh diri dengan pandangan sendiri,

Sangkar atas dahan yang lapuk tidaklah bisa menjadi aman" (Raliby, 1978:16).

Pada tahun 1922 Iqbal memperoleh gelar Sir dari Pemerintah Inggris Seorang bangsa Eropa secara kebetulan datang ke Lahore membaca syair-syair Muhammad Iqbal. Dari peristiwa tersebut ia ingin bertemu dengan Muhammad Iqbal. Gubernur kemudian mengundang Muhammad Iqbal ke Wisma Negara dan memperkenalkan kepada tamu tersebut. Kedua orang itu membicarakan berbagai macam mengenai sastra, filsafat dan seni. Muhammad Iqbal pulang ke rumah, sang tamu segera menemui Gubernur dan menyatakan dengan heran mengapa Pemerintah India tidak memberikan dan berbuat sesuatu untuk memberikan penghargaan kepada Muhammad Iqbal (Raliby, 1978: 16).

Gubernur selama itu tidak mengetahui tentang kepandaian dan keahlian Muhammad Iqbal, maka segera mengirim utusan ke London agar Muhammad Iqbal dianugerahi Sir dan hal tersebut disetujui, sehingga penyair dan sekaligus filsuf yang terkenal itu memperoleh gelar Sir Muhammad Iqbal. 
Pada tahun 1930 ia diangkat menjadi Presiden Liga Muslimin dan hadir dalam Perundingan Meja Bundar di London. Pada tahun 1933 ia menghadiri Konferensi Islam di Yerusalem, kemudian pergi ke Afghanistan untuk membicarakan pembentukan Universitas Kabul. Muhammad Iqbal meninggal pada usia 62 tahun pada tanggal 21 April 1938. (Widyastini, 2004:60-61).

\section{KARYA-KARYA PEMIKIRAN MUHAMMAD IQBAL}

Muhammad Iqbal memiliki karya yang tidak sedikit. Karya-karya Muhammad Iqbal tersebut dapat diklasifikasikan dalam tiga macam bahasa, yaitu:

\section{Bahasa Persia}

a) Rumuz-I-Bekhudi, diterbitkan di Lahore pada tahun 1918, adalah buku yang membahas mengenai individu dalam hubungannya dengan masyarakat.

b) Payam-I-Masyriq, diterbitkan di Lahore pada tahun 1923, adalah buku untuk menjawab syair Westoesteacheir Diwan dari Gothe \& Nicholson, yang berjudul Iqbalis Messege of the East dalam majalah Islamic.

c) Zabur-I-Ajam, diterbitkan di Lahore pada tahun 1927 adalah buku yang berisi jawaban atas pertanyaan yang berasal dari seorang sufi yang berjumlah 9 pertanyaan.

d) Javid Nemah, diterbitkan di Lahore pada tahun 1932, adalah buku yang berisi syair-syair yang dibimbing Jalaluddin Rumi.

e) Pas ceh Baid Kard aye Aqwam-I-Syarq, diterbitkan di Lahore pada tahun 1936, adalah buku yang berisi gubahan dalam wujud masnawi yang digubah pada waktu ia bertempat tinggal di Afghanistan.

f) Lala-I-Thur, diterbitkan di Lahore pada tahun 1937, buku diterjemahkan dalam bahasa Inggris oleh Prof. AJ. Arbery dengan judul The Tulip of Sinai.

g) Asrar-I-Khudi, diterbitkan di Lahore pada tahun 1945, adalah buku yang membahas mengenai human ego (diri manusia) (Iqbal, 1978: 270-271). 


\section{Bahasa Urdu}

a) Ilmu al-Iqtisad, diterbitkan di Lahore pada tahun 1903, adalah buku yang membicarakan tentang masalah ilmu ekonomi.

b) Bang-I-Dara, diterbitkan di Lahore pada tahun 1924, adalah buku yang berisi kumpulan syair-syair.

c) Bal-I-Jibril, diterbitkan di Lahore pada tahun 1935, adalah buku tentang syair-syair yang berarti sayap-sayap Jibril dan berisi do'a pada saat menjalankan sholat di Masjid Cordova, Spanyol.

d) Zarb-I-Kalm, diterbitkan di Lahore pada tahun 1936, adalah buku yang berisi syair-syair merupakan tinjauan dan saran berbagai segi dari kehidupan modern.

e) Armghan-I-Hijazi, diterbitkan di Lahore pada tahun 1938, adalah buku tentang syair-syair yang berbahasa Urdu dan Persia.

f) Iqbal Namah, Maqatib Iqbal, diterbitkan di Lahore pada tahun 1944, adalah kumpulan surat-surat yang berbahasa Urdu mengandung pemikiran-pemikiran Iqbal yang dijelaskan dalam berbagai macam surat kepada para pemimpin bangsa dan negara.

g) Iblis ki Majlis-I-Syura, diterbitkan di Gujarat pada tahun 1951, adalah buku yang berisi syair-syair yang berarti Permusyawaratan Iblis.

h) Baqiyat-I-Iqbal, diterbitkan di Lahore pada tahun 1954, adalah buku yang berisi syair-syair Iqbal yang belum pernah dipublikasikan. (Iqbal, 1978: 273).

\section{Bahasa Inggris}

a) Development of Metaphysics, diterbitkan di London pada tahun 1908, adalah sumbangan pemikiran Iqbal dalam sejarah filsafat Islam merupakan disertasi untuk memperoleh gelar PhD di Universitas Munchen, Jerman.

b) The Reconstruction of Religious Thought in Islam, diterbitkan di Lahore pada tahun 1934, adalah karya Iqbal dalam usaha menyusun dan membangun kembali filsafat Islam dengan mengutamakan pemikiran-pemikiran filosofis dalam menghadapi kemajuan-kemajuan yang aktual dalam berbagai macam ilmu pengetahuan. 


\section{MUHAMMAD IQBAL: \\ FILSUF DAN SUFI DALAM DUNIA ISLAM}

Muhammad Iqbal, dalam pandangan filsafatnya yang terdapat di dalam karya yang berjudul Lectures on Metaphysics, mengatakan bahwa dunia ini bukan sesuatu yang dapat diketahui dan dilihat melalui konsep-konsep, namun lebih merupakan sesuatu yang harus dibuat dan dibuat kembali. Daya kekuatan manusia yang terutama adalah kemauan sehingga senantiasa mengarah kepada suatu tahap kemanusiaan yang lebih mulia dan lebih tinggi yaitu berwujud cinta, kasih dan sayang dalam hidup manusia. Muhammad Iqbal dalam hal ini menganggap bahwa keindahan adalah sebagai hakikat dunia, kemudian daya kemauan atau kehendak mengarah kepada suatu perubahan.

Realitas berubah melalui suatu evolusi yang secara terus-menerus mewujudkan bentuk-bentuk baru. Setiap realita bersifat organis merupakan kehidupan yang berpusat pada suatu pribadi kosmis yaitu Tuhan (Allah). Pusat kehidupan terdapat dalam diri manusia yaitu perorangan atau individu pribadi tersebut (Van Peursen, 1980: 137).

Muhammad Iqbal memperoleh inspirasi dari filsafat Kant yang secara esensial bersifat empiris dan berhasil memperoleh pendekatan motivasi Islam yang beranggapan bahwa dunia adalah suatu fakta dan selalu menganggap penting pengalaman sebagai sumber pengetahuan dan memiliki tujuan yang sama. Ilmu pengetahuan dan filsafat mengutamakan pengalaman inderawi sebagai sesuatu yang penting, namun memiliki kecenderungan dan menganggap bahwa hanya ada dunia inderawi dan menolak realitas lain dalam dunia materi, sedangkan Islam mengakui terhadap adanya suatu realitas yang transendental.

Muhammad Iqbal berpendapat bahwa wahyu tidak dapat dicapai melalui panca indera dan rasio, karena harus berlindung pada suatu pengalaman yang memiliki ciri-ciri khusus yang disebut intuisi, karena seseorang dengan intuisi dapat menangkap dan memahami Realitas Mutlak (Tuhan) (Luce-Maitre, 1985:51).

Muhammad Iqbal meyakini bahwa intuisi sama dengan kemampuan untuk memperoleh pengetahuan lain, karena hal ini berhubungan dengan masalah perasaan, tetapi tidak sampai kepada subjektivisme. 
Perasaan pada dasarnya memiliki ciri khas yang bersifat kognitif sebab sama objektif dengan penglihatan. Seorang sufi berawal dari pemahaman Realitas Tertinggi dan cenderung memberi batas fungsi intuisi pada diri sendiri, maka menjadikan intuisi lebih dekat kepada pengalaman biasa dan dari intuisi tentang diri bergerak kepada intuisi mengenai Realitas Mutlak (Luce-Maitre, 1985:51).

Intuisi menunjukkan hidup sebagai ego yang bersifat fokus, pengetahuan ini adalah petunjuk langsung tentang sifat realitas yang sesungguhnya. Faktor-faktor pengalaman menghasilkan kesimpulan bahwa kodrat realitas yang sebenarnya adalah spiritual dan diibaratkan sebagai suatu ego, tetapi aspirasi agama lebih tinggi daripada filsafat. Filsafat adalah suatu pemikiran intelektual mengenai benda-benda sebagai suatu konsep segala sesuatu dan berbagai keragaman pengalaman ke dalam suatu sistem. Filsafat melihat Realitas dari kejauhan sedang agama mencari hubungan yang lebih dekat dengan Realitas.

Muhammad Iqbal selama bertahun-tahun memikirkan keadaan umat Islam dan menjelaskan sebab-sebab kelemahan umat Islam. Ia juga membahas tentang masa lalu dan masa kini berbagai bangsa serta filsafat yang melingkupi bangsa-bangsa tersebut. Muhammad Iqbal mengatakan bahwa filsafat dan agama adalah ujian intelektual yang dapat diterapkan pada pengalaman-pengalaman agama dan hal tersebut dapat diuji dalam meraih suatu kebenaran. Filsafat dan agama tidak bertentangan sebab merupakan satu aspek penting dari seluruh pengalaman mengenai realitas yang harus menjadi bahan renungan bagi filsafat (Fahry, 1970: 389).

\section{KONSEP PENDIDIKAN}

\section{DALAM PANDANGAN MUHAMMAD IQBAL}

Iqbal membagi pendidikan menjadi dua macam, yaitu: pendidikan watak dan pendidikan kreativitas.

\section{a. Pendidikan Watak}

Muhammad Iqbal berpendapat bahwa suatu teori pendidikan tidak dapat lepas dari kualitas dan watak manusia ideal. Manusia ideal menurutnya adalah manusia yang hidup dengan baik, penuh usaha 
dan perjuangan, bukan hidup yang tertutup, menarik diri atau mengasingkan diri, juga bukan hidup yang di dalamnya dipenuhi dengan kemalasan dan menganggap sesuatu serba ringan. Ia mengungkapkan dalam syairnya:

"Bila anda ingin melewati dunia sementara ini, Bila anda ingin beralih dari ketiadaan kepada keberadaan, Bertahanlah!

Jangan mudah anda melenyap, seperti kilatan cahaya sekejap!

Pupuk keberanian bersusah payah, agar berhasil meraih lumbung penuh melimpah!

Bila anda memiliki sinar matahari, beranilah menjelajah langit lazuardi!

Bila anda punya hati yang berani menantang panah, Hiduplah perkasa, dan matilah di dunia ini laksana rajawali!

Terapkanlah dalam kehidupan makna yang dalam dari ajaran, ibadah dan keimanan!

Hidup sekejap laksana singa,

Sebanding seratus tahun kehidupan tikus!"

(Saiyidain, 1981: 119-120).

Manusia hidup sehari-hari memiliki kegiatan aktif dengan lingkungannya dan secara dinamis merubah sesuai dengan maksud dan keperluan yang terdapat dalam dirinya. Sifat aktif yang terdapat dalam pendidikan watak terkandung dalam buku Asrar-I-Khudi (Rahasia Pribadi). Muhammad Iqbal berpendapat bahwa untuk mengembangkan pendidikan watak, maka hendaknya memiliki tiga sifat antara lain: keberanian, toleransi, faqr (keprihatinan).

\section{Keberanian}

Keberanian melaksanakan pendidikan watak dalam arti yang sebenarnya perlu adanya perencanaan secara cermat, sehingga dapat diperkirakan mampu memberi pengaruh yang dapat menimbulkan rasa 
dan sikap takut kepada pendidik. Takut kepada pendidik akan berakibat menurunkan dan menghambat kepekaan emosi, oleh karena itu perlu ditumbuhkan rasa cinta agar anak didik dapat mengembangkan diri sesuai dengan kemampuan dan kecerdasan yang dimilikinya. Keberanian dapat dikembangkan dan dijadikan salah satu bukti dari watak dengan cara menerapkan tauhid sebagai dasar kerja yang melandasi semua perbuatan.

Muhammad Iqbal mengatakan bahwa sikap tauhid mengandung arti menyerahkan semua permasalahan kepada Allah yang diawali dengan usaha atau ikhtiar, maka sikap tauhid menjiwai hak-hak asasi manusia. Karya Muhammad Iqbal yaitu Rumuz-I-Bekhudi mengungkapkan bahwa bila tauhid diterapkan dan dilaksanakan dalam hidup sehari-hari, maka akan menjadi obat yang mujarab untuk menghilangkan rasa takut, sifat pengecut dan putus asa.

Muhammad Iqbal dalam menghadapi hal-hal tersebut, membuat syair:

“Wahai, engkau yang terkurung dalam tempurung ketakutan,

Galilah hikmah ajaran Rasul yang terumus dalam laa tahzan!

Bila benar-benar kau beriman kepada Ilahi,

Bebaskan dirimu dari segala ketakutan!

Dan segala perhitungan untung-rugi!

Segala bentuk ketakutan selain kepada Allah

Menghambat segala tepak terjang.

Ketakutan adalah laksana perompak

Yang mengancam, menjegal kafilah,

Yang sedang melaju di perjalanan hidup!

Hidup tidak lagi mencerminkan diri!

Dan mereka yang benar-benar memahami

ajaran Muhammad Saw,

Akan menangkap basah diri syirik

Yang bersembunyi di dalam lubuk takut"

(Saiyidain, 1981: 128-129). 


\section{Toleransi}

Muhammad Iqbal mengatakan bahwa toleransi yang sebenarnya pasti tersirat dan memperoleh tempat pada setiap gambaran yang mengutamakan problem individualitas. Individualitas jika harus ditumbuhkembangkan secara maksimal bagi semua warga masyarakat dan dihadapkan pada sikap tidak toleran pasti akan gagal dan mengalami kehancuran, karena akan menimbulkan pertentangan abadi dan menghalangi serta menghambat adanya perkembangan.

Muhammad Iqbal dalam karya yang berjudul Bal-I-Jibril mengungkapkan dengan semangat sikap menghargai kepada kebenaran dan cinta kepada sesama umat manusia serta menolak sikap yang membabibuta berdasar kepada loyalitas, ajaran-ajaran yang sempit serta mementingkan golongan masing-masing.

Toleransi menurut Muhammad Iqbal adalah toleransi orang yang beriman, penuh percaya diri dan dijalin dengan rasa kasih sayang disertai kesadaran dan menghargai sifat-sifat yang dimiliki orang lain, hal ini diungkapkan dalam syairnya:

"Agama adalah damba abadi akan kesempurnaan,

Berpangkal pada pengabdian,

Berujung pada kasih,

Adalah dosa untuk menghamburkan sumpah serapah,

Mukmin maupun kafir sama-sama makhluk Allah.

Apakah "Adamiyah" itu? Apakah inti kemanusiaan?

Inti kemanusiaan adalah menghormati kemanusiaan!

Belajarlah untuk menghormati

Manusia adalah penuh cinta

Melangkah dijalan Allah

Yang iman dan tak beriman sama-sama dapat tempat

Bila hati bertiada kasih,

Apa gerangan akan terjadi?

Hati akan terkunci rapat-rapat,

Terbelenggu di penjara tanah liat,

Padahal seluruh semesta 
Adalah tempat hati bertahta"

(Saiyidain, 1981: 133-134).

\section{Faqr (Keprihatinan)}

Muhammad Iqbal tidak menerima ide peniadaan diri sebagai pengaruh dari Neo-Platonisme dan mistisisme, karena ia mendukung sikap hidup yang aktif dalam mengalahkan dunia materi, walaupun secara nyata bahwa sebagian besar orang banyak terbelenggu oleh keinginan dan semangat untuk memperbanyak hidup dengan materi.

Faqr dapat diibaratkan sebagai "ascetisme" (zuhud) dari segi pemikiran dan emosional dengan tidak berpaling dari dunia sebagai sumber penyimpangan, namun memanfaatkan dunia dalam upaya mencapai maksud baik, bermakna dan mengandung nilai-nilai keutamaan. Faqr menjadikan manusia seperti pejuang rohani yang tangguh, merupakan perisai yang memberi perlindungan bagi penganutnya dalam setiap langkah dan tindakannya. Muhammad Iqbal mengungkapkan dalam syairnya:

"Di saat jaya maupun masa nestapa,

Faqritu sebagai perisai

Pendukung dan pelindung,

Pejuang berhati murni."

"Sikap menghindar dari dunia dan materi,

Bukan tujuan dari zuhud yang murni

Zuhud justru berarti penaklukan langit dan bumi!

Yang punya duka dan nestapa!

Bangsa yang tak punya keberanian seperi Timur

Takkan mampu memupuk dan menempa

Manusia berjiwa "faqr".

Dan takkan pula mampu menaklukkan penjajah!"

(Saiyidain, 1981:135-136).

Pendidikan bagi Muhammad Iqbal adalah pendidikan yang dijiwai semangat dan cita-cita merupakan sumber inspirasi bagi tata kehi- 
dupan sosial dan kebudayaan, maka seharusnya pendidikan bersifat dinamis dan kreatif didasarkan pada kemauan dan kemampuan agar dapat menguasai seni, ilmu pengetahuan, kecerdasan dan kekuatan. Pendidikan tersebut adalah pendidikan yang berbasis keyakinan yang optimis mengenai tujuan akhir hidup manusia.

Muhammad Iqbal berpendapat bahwa ilmu pengetahuan memiliki peranan penting, maka manusia tidak hanya mampu menguasai alam, namun mampu mengawasi dan menggunakan metode-metode ilmiah sehingga dapat menata kembali hidupnya sesuai dengan citacita dan semangat dalam menghadapi realitas. (Saiyidain, 1981:170).

Muhammad Iqbal mengakui secara jelas bahwa ilmu pengetahuan pada zaman modern ini memiliki bobot dan makna sedemikian rupa bagi pendidikan, namun disadari pula bahwa ilmu pengetahuan hanya mampu menerima kebenaran sementara, maka dalam hal ini hanya dapat mewakili satu metode saja dalam memberikan gambaran secara menyeluruh dalam menghadapi dunia realita.

Muhammad Iqbal mengatakan bahwa agama dapat memberikan gambaran dan pemahaman mengenai dunia kenyataan secara lengkap dan menyeluruh, maka agama mempunyai kedudukan yang pertama dan utama. Agama tidak dipertentangkan dengan ilmu pengetahuan, namun agama lebih merupakan penyempurna yang dapat mengimbangi pemikiran yang diperoleh dalam ilmu pengetahuan. Agama adalah sumber yang demikian penting bagi kehidupan manusia, sehingga hal-hal yang bersifat religius dapat diraih untuk kemaslahatan umat manusia. (Saiyidain, 1981:171).

Muhammad Iqbal berpendapat bahwa kebenaran yang diperoleh dari akal pikiran tidak dapat membangkitkan semangat hidup yang mendalam pada pribadi manusia, sedangkan agama lebih berhasil membangkitkan harkat martabat individu dan bahkan mampu mengubah masyarakat seluruhnya. Agama dapat menggugah kembali sikap penuh keyakinan bagi manusia, sehingga dapat tampil sebagai pribadi, baik saat ini hingga masa-masa yang akan datang. Agama yang diartikan dalam hal ini adalah agama yang memiliki manivestasi setinggi mungkin demi terwujudnya kebahagiaan hidup di dunia dan di akhirat (Saiyidain, 1981:172). 
Pandangan hidup bagi Muhammad Iqbal adalah cerminan pandangan yang berdasarkan pada jiwa religiusitas yang mendasari semua kehidupan, maka pendidikan seyogyanya dijiwai oleh semangat dan jiwa keagamaan secara mendasar. Corak dan sistem pendidikan hendaknya mempersiapkan dan melengkapi siswa didik bagi suatu kehidupan yang dinamis dan penuh semangat dan keaktifan. Tujuan pendidikan yang dimaksud adalah mendidik individu agar menjadi jati diri yang mantap dapat mewujudkan dirinya dalam semangat hidup yang penuh dengan berbagai kegiatan (Saiyidain, 1981: 177).

Manusia merupakan makhluk yang aktif, dapat berbuat, mampu mencapai maksud dan tujuan sehingga dapat membentuk dan menata ulang dengan menumbuhkembangkan dan meningkatkan individunya secara lebih kreatif untuk memperoleh suatu kemajuan. Sistem pendidikan bagi Muhammad Iqbal adalah meraih tempat bagi terwujudnya hubungan dengan diri (yang sedalam-dalamnya) dengan alam semesta dan hubungan ini adalah suatu persiapan adanya hubungan yang Maha Mutlak yaitu Allah SWT (Saiyidain, 1981: 178).

Muhammad Iqbal bertanya, apakah pendidikan mempunyai cita-cita yang tinggi dan tetap pada kedudukan yang rendah dalam menemukan pancaran Ilahi dalam diri manusia serta menumbuhkembangkan kualitas pancaran Ilahi agar dapat mengelola dunia yang pantas bagi manusia? Muhammad Iqbal mengemukakan sajaknya dalam Bal-I-Jibril.

“Dunia ini yang penuh polusi karena kacauan warna dan kacauan suara,

Dunia ini; dimana kematian merajalela, dunia ini yang penuh pengamatan semu, bergelimang dalam suara sumbang,

Dunia ini; dimana arti hidup hanyalah makan dan minum,

Dunia ini-wahai pengembara-

Barulah lintas pertama dalam perjalanan Ego

Dunia ini-sekali-kali-bukan tujuanmu!

Hingga luluh gambaran salah tentang ruang dan waktu ini

Masih banyak dunia belum tertempa

Bagi jiwa mencipta yang tak pernah hampa! 
Semua tak sabar menanti kelanjutanmu yang gemilang, Serta ketajaman jiwamu dan kecermatan tindakanmu Mengapa pula roda waktu berputar terus Agar Egomu membentang jelas di hadapanmu! Engkaulah penakluk dunia baik dan buruk, Tak kuasa aku merentangkan nasibmu di hadapanmu Hatiku benderang mandi cahaya inspirasi, Namun kekuatanmu kata tak mampu menari seirama! Sekiranya saja akan melangkah laju seujung rambut, Niscaya sinar yang semarak akan membakar Sayapku yang sedang mengawang membumbung tinggi". (Saiyidain, 1981: 178-179).

\section{KONSEP PENDIDIKAN BANGSA INDONESIA}

\section{YANG BERBASIS PADA SILA-SILA PANCASILA}

\section{a. Beberapa Pandangan tentang Pendidikan} dan Pendidikan Pancasila

1. Pendidikan menurut Al-Ghazali adalah ibadah dan sarana reformasi sosial, karena hanya pendidikan yang dapat mengembangkan keutamaan, membersihkan jiwa dan merupakan proses pendekatan seseorang kepada Allah SWT. Pendidikan yang diberikan secara baik dan benar adalah tempat untuk menyebarluaskan dan menumbuhkembangkan keutamaan-keutamaan kepada umat manusia. Al-Ghazali mengemukakan tujuan pendidikan sesuai dengan pemikiran filosofisnya yang religius dan sufistis, artinya bahwa siswa didik hendaknya diberikan ilmu pengetahuan yang di dalamnya mengandung nilai-nilai moral dan agama, sehingga dapat memberikan manfaat tidak hanya untuk meraih keutamaan di dunia namun juga di akhirat. Al-Ghazali juga menjelaskan bahwa menuntut ilmu adalah suatu kewajiban baik bagi seorang muslim maupun muslimah, sehingga pendidikan menuntut hubungan yang baik antara pendidik dan siswa didik. (Sulaiman, 1986:3-5).

2. Imam Barnadib mengatakan bahwa pendidikan adalah pengetahuan ilmu terdiri atas dasar dan fakta, maka bersifat abstrak. Pendi- 
dikan di Indonesia berlandaskan Pancasila yaitu nilai-nilai dan norma-norma yang berasas Pancasila, misalnya keadilan. Keadilan sebagai suatu nilai memiliki sifat abstrak dan akan berubah menjadi konkret jika dilaksanakan dalam bidang tertentu, seperti dalam bidang hukum, karena dirasa tidak pada tempatnya jika dalam proses pendidikan seseorang tidak memperoleh bekal tentang teoriteori yang bersifat abstrak dan perlu mengetahui tujuan yang akan dicapai. (Barnadib, 2002: 5).

3. Proses pendidikan, menurut Kaelan, di dalamnya terdapat beberapa macam pelajaran atau mata kuliah yang memperoleh perhatian yang demikian luas, yaitu pendidikan moral yang bertujuan pada pengembangan nilai-nilai kepribadian berupa nilai-nilai karakteristik baik bagi para pendidik maupun para siswa didik. Manusia sebagai makhluk individu dan makhluk sosial hendaknya dapat saling berinteraksi satu dengan yang lain secara baik dan seimbang sehingga dapat menumbuhkan sifat, sikap, kebiasaan, perilaku, perbuatan, tabiat, serta karakter atau ciri khas yang memberikan perbedaan antara manusia satu dengan yang lain (Kaelan, 2012: 8).

Kaelan berpendapat bahwa pendidikan bangsa Indonesia yang berdasar pada Pancasila memiliki tujuan:

1) Mampu mengambil sikap yang penuh tanggung jawab sesuai dengan hati nurani.

2) Mampu mengetahui persoalan hidup dan kesejahteraan serta menemukan cara-cara penyelesaiannya.

3) Mengetahui perubahan dan perkembangan ilmu pengetahuan, teknologi dan seni.

4) Mampu memberikan makna terhadap sejarah dan nilai-nilai budaya bangsa dan Negara dalam upaya mewujudkan Negara Kesatuan Republik Indonedia yang berwilayah dari Sabang sampai Merauke (Kaelan, 2014: 6-7).

Notonagoro berpendapat bahwa sila-sila Pancasila adalah corak khas bangsa Indonesia dan merupakan pembeda bangsa Indonesia dengan bangsa-bangsa lain di dunia yang digambarkan dengan perikehi- 
dupan bangsa Indonesia, dipengaruhi situasi dan kondisi Indonesia berupa hidup gotong royong, kekerabatan, ketuhanan, kerakyatan, kemanusiaan, persatuan, keadilan, keramahtamahan dan memiliki sifatsifat Bhinneka Tunggal Ika (berbeda-beda tetapi tetap satu jua) (Notonagoro, 1987: 195-196).

Kaelan berpendapat bahwa Pancasila, dasar filsafat bangsa Indonesia, berperan sebagai national identity yang mempunyai legitimasi, sejarah, kebudayaan, filsafat, politik dan hukum. Pendidikan Pancasila di dalamnya terkandung pengembangan moral kenegaraan, kemanusiaan, kebudayaan dalam multikulturalisme dan etika politik.

Pendidikan bagi bangsa Indonesia berbasis pada nilai-nilai luhur Pancasila, maka Pancasila adalah core values dalam membentuk kepribadian bangsa dalam perwujudannya diawali dengan kepribadian individu. Basis nilai-nilai yang terdapat dalam Pancasila terdiri atas nilai-nilai Ketuhanan, Kemanusiaan, Persatuan, Kerakyatan dan Keadilan.

Sumber kajian dalam mata kuliah atau mata pelajaran Pancasila, bangsa Indonesia tidak hanya menumbuhkembangkan nilai-nilai religius, moralitas, kemanusiaan, toleransi, kebersamaan dan perbedaan, tetapi juga secara ilmiah adalah berupa sumber pengembangan ilmu pengetahuan dalam dunia pendidikan. (Kaelan, 2012: 20-21).

\section{EVALUASI KRITIS TERHADAP KONSEP PENDIDIKAN MUHAMMAD IQBAL DAN RELEVANSINYA DENGAN PEMBANGUNAN KARAKTER BAGI BANGSA INDONESIA}

Konsep pendidikan Muhammad Iqbal terdiri atas pendidikan watak dan pendidikan kreativitas. Pendidikan watak merupakan halhal yang berkaitan dengan keberanian, toleransi dan faqr (keprihatinan).

Keberanian berawal dari adanya rasa takut siswa didik kepada pendidik yang menurut Muhammad Iqbal harus disertai dengan penerapan tauhid, artinya pasrah secara total kepada Allah SWT, namun disertai usaha agar dapat mencapai cita-cita dan tujuan hidup yang akan dicapai. 
Toleransi yang dimaksud Muhammad Iqbal adalah toleransi sesama orang beriman, memiliki rasa percaya diri (self confidence) dan dilandasi cinta kasih dengan penuh kesadaran serta adanya sifat saling menghargai dan menghormati orang lain, sehingga tumbuh adanya kerjasama yang baik demi harkat dan martabat sebagai manusia.

Faqr (keprihatinan) bagi Muhammad Iqbal adalah ascetisme (zuhud) yaitu menjalani kehidupan dengan tidak meninggalkan hal-hal yang bersifat keduniaan (materi), namun tetap berada pada jalan kebenaran dan keutamaan untuk meraih kehidupan rohani yang bahagia dalam menggapai ridho Ilahi.

Muhammad Iqbal berpendapat bahwa pendidikan kreativitas adalah pendidikan yang berbasis religiusitas penuh dengan semangat, dinamis, dan optimis dalam rangka mencapai tujuan hidup manusia, maka diperlukan adannya hidup yang menyeimbangkan antara ilmu pengetahuan dengan ilmu agama sedemikian rupa sehingga terwujud kebahagiaan di dunia dan di akhirat (Saiyidain, 1981: 128, 129, 133, 134, 170,171).

Konsep-konsep pendidikan Muhammad Iqbal tersebut secara kritis dapat dievaluasi sebagai berikut:

1) Muhammad Iqbal dalam mengemukakan beberapa pandangan tentang konsep pendidikan dirasakan terdapat kerancuan. Di satu sisi ia berbicara tentang masalah pendidikan, namun di sisi lain yang dibicarakan adalah pendidikan yang diarahkan kepada tipe manusia ideal. Adapun manusia ideal yang sebenarnya hanya ada pada diri Nabi Muhammad Saw.

2) Pendidikan bagi Muhammad Iqbal hendaknya dilaksanakan dan dibimbing semangat liberal dan berpandangan luas. Liberal yang dimaksud dalam hal ini sudah pasti bukan hal yang mengarah kepada kebebasan yang benar-benar bebas, namun kebebasan dalam koridor memiliki keleluasaan memahami sesuatu hal sehingga tidak menyimpang dari tujuan hidup manusia sebagai khalifah Allah.

3) Sistem pendidikan yang dimaksud Muhammad Iqbal tidak hanya pendidikan watak dan kreatifitas saja, tetapi pendidikan dalam ru- 
ang lingkup kehidupan yang bersifat kemanusiaan, sehingga diharapkan adanya saling menghargai, saling menghormati, saling kerjasama dan penuh toleransi di antara sesama umat manusia.

Muhammad Iqbal dengan konsep pendidikan yang terdapat di dalam beberapa karyanya ditemukan adanya beberapa relevansi dengan pembangunan karakter bagi bangsa Indonesia, yaitu:

1) Pendidikan watak yang dikemukakan Muhammad Iqbal terutama berkaitan dengan kedudukan yang diperoleh manusia demikian tinggi, namun hendaknya tetap dapat mengendalikan diri pada kedudukan yang terhormat, maka akan selalu berusaha berada di jalan Allah. Relevansinya dengan pembangunan karakter bagi bangsa Indonesia yaitu bangsa Indonesia dikenal sebagai bangsa yang religius, hal ini dapat dibuktikan bahwa mayoritas bangsa Indonesia beragama Islam selalu berusaha taat sebagai hamba-hamba Allah yang beriman dan bertakwa sesuai dengan ajaran agama Islam.

2) Konsep pendidikan yang dikemukakan oleh Muhammad Iqbal menekankan adanya rasa keberanian siswa didik kepada pendidik, maka diperlukan adanya semangat, cita-cita dan dinamisasi sedemikian rupa yang terdapat dalam suatu lembaga pendidikan, sehingga terwujud interaksi sosial yang baik antara siswa didik dengan pendidik.

3) Konsep pendidikan bagi bangsa Indonesia berlatar belakang dan berbasis pada sila-sila Pancasila, maka pendidikan yang diutamakan adalah pendidikan moral keagamaan dan moral kenegaraan, sehingga menghasilkan siswa didik dan pendidik yang berjiwa Pancasila.

4) Muhammad Iqbal dalam konsep pendidikan kreatifitas mengemukakan adanya sinergi antara ilmu pengetahuan dan agama yang akan menghasilkan suasana pendidikan memiliki nilai-nilai ilmiah dan nilai-nilai religiusitas yang tinggi.

5) Pendidikan kreativitas yang terdapat dalam sila-sila Pancasila adalah pendidikan yang penuh dengan multikulturalisme yang tersebar dalam berbagai tradisi, adat-istiadat, budaya dan agama bangsa Indonesia. 


\section{SIMPULAN}

Berdasarkan uraian di atas, dapat diambil simpulan sebagai berikut:

1. Pendidikan merupakan suatu keharusan yang hendaknya diarahkan untuk menghidupkan kembali dan memberikan kekuatan pada individualitas manusia, sehingga dapat terwujud suasana pendidikan yang menyejukkan dan menentramkan antara siswa didik dengan pendidik.

2. Pendidikan berupaya menemukan dan merevitalisasi sumber-sumber kebudayaan nasional dengan memberikan manfaat, sehingga memberikan hasil kegiatan yang kreatif penuh semangat disertai cita-cita untuk mencapai tujuan hidup manusia.

3. Hakikat relevansi pemikiran Muhammad Iqbal tentang pendidikan dengan pembangunan karakter bagi bangsa Indonesia dapat memberikan inspirasi bagi setiap manusia Indonesia agar senantiasa dapat mawas diri terhadap pendidikan yang selama ini dilaksanakan.

4. Pendidikan yang diharapkan adalah sesuai dengan nilai-nilai luhur yang terdapat dalam sila-sila Pancasila, yaitu nilai-nilai moral kenegaraan dan nilai-nilai moral keagamaan.

5. Pendidikan yang sesuai dengan karakter bangsa Indonesia adalah pendidikan yang mengutamakan kepribadian dengan mewujudkan keseimbangan berupa kebahagiaan lahiriah dan batiniah, kebahagiaan material dan spiritual yang berada di wilayah Negara Kesatuan Republik Indonesia yang ber-Bhinneka Tunggal Ika.

\section{DAFTAR PUSTAKA}

Alwasilah, A. Chaidar, 2008, Filsafat Bahasa dan Pendidikan, Remaja Rosdakarya, Bandung.

Azzam, Abdul Wahab, 1985, Filsafat dan Puisi Iqbal, diterjemahkan oleh Ahmad Rofi' Usman, Pustaka Salman ITB, Bandung.

Barnadib, Imam, 1997, Filsafat Pendidikan Sistem dan Metode, ANDI, Yogyakarta.

2002, Filsafat Pendidikan, Adi Cita, Yogyakarta. 1996, Dasar-Dasar Kependidikan, Memahami Makna 
144 Jurnal Filsafat, Vol. 27, No. 1, Februari 2017

dan PerspektifBeberapa Teori Pendidikan, Ghalia Indonesia, Jakarta.

Effendi, Djohan \& WM Abdul Hadi, 1986, Iqbal Pemikir Sosial Islam dan Sajak-Sajaknya, Pancasimpati, Jakarta.

Fahry, Majid, 1970, A History of Islamic Philosophy, Columbia University Press, New York and London.

Iqbal, Muhammad, 1996, Membangun Kembali Pikiran Agama dalam Islam, Tintamas, Djakarta.

Kaelan, 2012, Pendidikan Pancasila Dalam Pembentukan Karakter Bangsa, Fakultas Filasafat Universitas Gadjah Mada, Yogyakarta. 2014, Pendidikan Pancasila, Paradigma, Yogyakarta.

Luce, Miss-Maitre Claude, 1985, Pengantar Kepemikiran Iqbal, diterjemahkan oleh Johan Effendi, Mizan, Bandung.

Saiyidain, K. G, 1981, Percikan Filsafat Iqbal Mengenai Pendidikan, Diterjemahkan oleh M. I. Soelaeman, CV Diponegoro, Bandung.

Qadir, C.A, 1989, Filsafat dan Ilmu Pengetahuan dalam Islam, diterjemahkan oleh Hasan Basyari, Yayasan Obor Indonesia, Jakarta.

Van Peursen, C.A, 1980, Orientasi di Alam Filsafat, (Sebuah Pengantar dalam Permasalahan Filsafat, diterjemahkan oleh Dick Hartoko, Gramedia, Jakarta.

Widyastini, 2004, Filsafat Manusia Menurut Confucius dan Al-Ghazali, Paradigma, Yogyakarta. 